\title{
Urinary Tract Infection in Nephrotic Syndrome in Pediatric Age Group: A Hospital Based Cross- sectional Study.
}

Subhendu Samanta ( $\nabla$ samantasubhendu244@gmail.com )

BSMCH,WB,India

\section{Research Article}

Keywords: UTI, urinary tract infection, nephrotic syndrome, hematuria, pyuria.

Posted Date: June 18th, 2020

DOI: https://doi.org/10.21203/rs.3.rs-36334/v1

License: (c) (i) This work is licensed under a Creative Commons Attribution 4.0 International License. Read Full License 


\section{Abstract}

Background::Nephrotic syndrome, characterized by the presence of heavy proteinuria, hypoalbuminemia, edema and hyperlipidemia, is a common renal disorder in pediatric population. Aim of this study were to find out the prevalence of UTI in nephrotic syndrome, bacterial etiologies and antibiotic sensitivity pattern.

Methods:After matching the criteria, 82 cases, were taken for this prospective, single center, observational study.The diagnosis was confirmed by bacterial culture. This is an institution based cross-sectional descriptive observational study. All newly diagnosed and relapse cases of nephrotic syndrome based on inclusion exclusion criteria was included in this study. Respondent was either of the parents or caregiver of the study subjects. Analysis of all data was done by appropriate statistical software(SPSS-23).

Results:Among 82 participants evaluated with nephrotic syndrome 29.3\% participants had Urinary Tract Infection ,majority $66.7 \%$ were asymptomatic and $33.3 \%$ were symptomatic. Significant microscopic hematuria were found in $20.7 \%$ study subjects and significant pyuria were found in $58.54 \%$ study subjects. Majority of UTI caused by E.coli $33.3 \%$ followed by Klebsiella 25\%,Proteus $16.7 \%$,Staphylococcus aureus $12.5 \%$,Citrobacter,Acenetobacter and mixed growth werefound in $4.2 \%$ each.Mean serum cholesterol of group with UTI was $422.13 \pm 34.65$ and group without Urinary Tract Infection was $307.43 \pm 26.13$. The variation amongst the two groups were found to be significant $(P=0.0001)$.

Conclusions:The children with nephrotic syndrome are frequently predisposed to Urinary Tract Infection and in most cases it is asymptomatic, often undiagnosed. Higher serum cholesterol level may predispose the nephrotic child for Urinary Tract Infection.

\section{Introduction}

Nephrotic syndrome is characterized by the presence of heavy proteinuria, hypoalbuminemia, edema and hyperlipidemia, a common renal disorder in pediatric population. ${ }^{1}$ Clovin and Goldberg used the term "Nephrotic Syndrome" to describe patient with edema, proteinuria and hyperlipidemia. Synthesized steroid hormones were used as a treatment of nephrotic syndrome since $1950^{2,3}$. Nephrotic syndrome is a common clinical condition in Asian children. ${ }^{4}$ The prevalence of minimal change nephrotic syndrome (MCNS) is also higher in Indian subcontinent. ${ }^{5}$ There is a racial variation in susceptibility with a reported in incidence in Asian children of $9-16 / 100,000,5,6$ in comparison to 2 to 7 children in USA, 2-4 new cases $/ 100,000$ children in UK. ${ }^{7,8}$ The pathogenesis of nephrotic syndrome still not identified. Abnormalities in the functions of the T lymphocytes, in particular the suppressor T cells and the generation of circulating factors capable of altering the permeability of glomerulus to proteins seem to be involved in the pathogenesis of the nephrotic syndrome. ${ }^{9}$ These patients have an increased risk of developing bacterial infections due to defective cell mediated immunity, immunosuppressive therapy, malnutrition, and urinary losses of immunoglobulins, properdin factor $B$ and complement factors. ${ }^{10}$ Specially in developing countries as our infection is that one of the most important complications in nephrotic syndrome. Infection may lead to poor response to steroid and frequently results in relapse in a child who has already attained remission. ${ }^{11,12}$ Among all infections urinary tract infection is of special interest because most of the urinary tract infections in nephrotic 
syndrome are asymptomatic. ${ }^{13}$ Besides, in general, younger the child, the sign symptoms of urinary tract infection are less localizing. ${ }^{14} \mathrm{So}$ it is often undiagnosed and important cause of prolonged hospital stay having a propensity for long-term renal damage, ${ }^{11,15} \mathrm{UTI}$ if left untreated in a patient of nephrotic syndrome who has been started on steroid therapy will complicate the course of both the UTI and nephrotic syndrome. ${ }^{16}$ UTI in Nephrotic syndrome is associated with significantly lower serum albumin and also with higher serum cholesterol levels. ${ }^{17}$ Hypercholesterolemia is thought to inhibit lymphocytic function thus may have direct role in precipitation of infection. Assessment of magnitude of problem would add to the existing figures of UTI prevalence which varies from study to study. Delineation of bacterial spectrumwillhelp in selecting the empirical antibiotic therapy in UTI till the results of culture are awaited. Objective of the present study is to find out the prevalence of UTI in nephrotic syndrome, bacterial etiologies and antibiotic sensitivity pattern.

\section{Methods}

This is an institution based(single centre) cross-sectional descriptive observational study conducted in pediatric medicine department of BankuraSammilani Medical College and Hospital during the period of February, 18 to July, 2019.During the present study period, a total of 412 patients ( 258 male and 152 female) with nephrotic syndrome, attended/admitted the out-patient/in-patient department of Paediatric Medicine. All newly diagnosed and relapse cases of nephrotic syndrome based on inclusion exclusion criteria was included in this study. Respondent was either of the parents or caregiver of the study subjects.

Inclusion criteria: All patients with the age group between 2-12 years, attending Paediatric out-patient department or admitted in Paediatric in-patients Department with the diagnosis of Nephrotic Syndrome was included in this study. Ethical approval and consent to participate was obtained from the Institutional Ethics Committee, BSMCH, Kolkata, West Bengal, India. Approval letter (Memo No. BSMC/aca/44dt02.01.18) is available for review by the editor of the journal. Written informed consent for participation in the study was obtained.

Exclusion criteria-

1. Children with gross urogenital anomalies.

2. Nephrotic syndrome with atypical presentation- hypertension, gross hematuria.

3. Nephrotic syndrome with features of complications other than UTI.

4. $\mathrm{H} / \mathrm{O}$ of taking antibiotic during last 15 days prior to Admission.

5 . Where patient's care giver was unwilling to give consent.

The gathered data was entered in SPSS-23 software and to describe the data, frequency tables, statistical indicators and diagrams were used. To analyze the relationships between variables, related tests including the chi-square test, t-test were used. 


\section{Results}

A total of 82 patients were finally enlisted and evaluated. Thorough history taking, clinical examination and laboratory investigations were done as per case record form with special emphasis on detection of UTI in enlisted nephrotic patients. Then data were compiled and analysed. The following observations were made as given below.

\section{Baseline characteristics was depicted in [Table 1]}

Analysis revealed that majority of patients $63(76.83 \%)$ belonged to age group 2-7years. The overall average age was estimated as $5.59 \pm 1.89$ (mean $\pm s d$ ) years. Median age was 5.05 years with a range of 8.4 years. Out of 49 male patients $38(77.6 \%)$ belonged to age group 2-7 years and $11(22.4 \%)$ belonged to $7-12$ years. Out of 33 female patients $25(75.8 \%)$ belonged to $2-7$ years and $8(24.2 \%)$ belonged to $7-12$ years. Among 82 participants, there was a male predominance $59.76 \%(n=49)$. Male: Female=1.49:1.

[Figure -1] Shows distribution of participants by their UTI status $(n=82)$ and distribution of participants with UTI by symptoms ( $n=24)$ Among 82 participants with nephrotic syndrome $29.3 \%(n=24)$ participants had UTI.Among participants with UTI majority $19 \%(n=16)$ were asymptomatic and $10 \%(n=8)$ were symptomatic.

Bar diagram in [Figure-2]shows distribution of pyuria and hematuria among participants $(n=82)$

In present study among 82 participants of nephrotic syndrome significant microscopic hematuria were found in $20.7 \%(n=17)$ study subjects and significant pyuria were found in $58.54 \%(n=48)$ study subjects.

Pie diagram [Figure -3] shows causative agents of UTI isolated in the present study $(n=24)$

Majority of UTI caused by E. coli $33.3 \%(n=8)$ followed by Klebsiella $25 \%(n=6)$, Proteus $16.7 \%(n=4)$, Staphylococcus aureus $12.5 \%(n=3)$, Citrobacter, Acenetobacter and mixed growth were found in $4.2 \%(n=1)$ each.

Urine culture sensitivity pattern of present study is shown in [Table-2].Present study revealed that majority of UTI caused by E.coli 33.3\% $(n=8)$ followed by Klebsiella 25\% $(n=6)$, Proteus 16.7\% $(n=4)$, Staphylococcus aureus $12.5 \%(n=3)$, Citrobacter, Acenetobacter and mixed growth were found in $4.2 \%(n=1)$ each. It was found that Amikacin (81\%), Ofloxacin (80\%), Cefixime (90\%) Meropenem (79.2\%) ,Nitrofurantoin $(72.2 \%)$, Piperacillin + Tazobactum (95.2\%) were very much effective against most of the culture isolates. Where as Staphylococcus aureus was found to be susceptible to Amoxyclav (100\%), Meropenem (66.7\%) and Linezolid (66.7\%). Minor isolates were also found to be susceptible to most of the antibiotics.

In the present study population group Acomprised of Nephrotic syndrome with UTI, and group B comprised of Nephrotic syndrome without UTI. 
[Table -3] showsbaseline parameters among two groups. The study revealed that mean $\mathrm{Hb} \%$ of group $\mathrm{A}$ was $10.23 \pm 0.75$ and group $B$ was $10.43 \pm 0.75$. However the variation amongst the two groups were not found to be significant $(p=0.28)$.Average E.S.R of group A was $44.80 \pm 10.15$ and group $B$ was $40.33 \pm 10.45$. This difference was not statistically significant $(p=0.09)$. Mean TLC of group $A$ was $11538.33 \pm 1282.19$ and group $B$ was $11074.83 \pm 1575.59$. The variation amongst the two groups were not found to be significant $(p=0.11)$.

In the present study mean serum protein of group A was found to be $4.26 \pm 0.27$ and group $B$ was found to be $4.24 \pm 0.29$. However the variation amongst the two groups were not found to be significant $(p=0.87)$.Average serum albumin of group $A$ was $2.36 \pm 0.16$ and group $B$ was $2.41 \pm .20$. This difference was not statistically significant $(p=0.30)$. Mean serum cholesterol of group $A$ was $422.13 \pm 34.65$ and group $B$ was $307.43 \pm 26.13$. The variation amongst the two groups were found to be significant $(P=0.0001)$.Average serum urea of group $A$ was $17.13 \pm 2.25$ and group $B$ was $16.75 \pm 2.30$. This difference was not statistically significant $(p=0.49)$. Mean serum creatinine of group $A$ was $0.69 \pm 0.09$ and group $B$ was $0.68 \pm 0.08$. The variation amongst the two groups were found to be insignificant $(p=0.58)$.

[table-4] shows comparison of serum albumin and serum cholesterol values between two groups among different studies.

\section{Discussion}

The nephrotic syndrome is an immune compromised state and hence host is susceptible to a variety of infections. This could be due to decreased serum immunoglobulin, protein deficiency, decreased bactericidal activity of the leukocytes, immunosuppressive therapy, decreased perfusion of the spleen caused by hypovolemia and loss of a complement factor3 (Properdin factor 3 ) in urine that opsonizes bacteria. The pressure exerted by edematous pyramids on the collecting system causes narrowing and functional obstruction to the flow of urine, further predisposing them to UTI. Of all the infections in children, Urinary Tract Infections (UTI) is significant because it can lead to long term renal damage. In current study, majority patients $63(76.83 \%)$ belonged to age group 2-7 years. The overall average age was estimated as $5.59 \pm 1.89$ (mean \pm sd) years. Median age was 5.05 years with a range of 8.4 years.In our study regarding clinical profile of the patient it was observed that participants with UTI majority $16(66.7 \%)$ were asymptomatic and 8 (33.3\%) were symptomatic. In present study microscopic examination of urine showed pyuria in $15(62.5 \%)$ in nephrotic syndrome with UTI patients and in $33(56.9 \%)$ in nephrotic syndrome without UTI ( $p$ value $>0.05$, not significant). Microscopic hematuria was found in 8 (33.3\%) of UTI patients \& in $9(15.5 \%)$ of without UTI patients that was not statistically significant ( $p$ value $>0.05$ ). In the present study attacks of the nephrotic syndrome (first episode or relapse) was not found to be significant between the UTI groups and non UTI groups.In present study the age, gender, ethnicity, religion, serum albumin, total protein, haemoglobin, erythrocyte sedimentation rate, serum creatinine, serum urea were not statistically significant between the UTI groups and non UTI groups. Mean serum cholesterol of nephrotic syndrome with UTI group was $422.13 \pm 34.65$ (mean \pm sd) and nephrotic syndrome without UTI group was $307.43 \pm 26.13$ (mean $\pm s d$ ). The variation amongst the two groups were found to be significant $(P=0.0001)$.In the present study conducted over 82 nephrotic syndrome patients, UTI was found in 24(29.30\%) of 
cases. The results of this study showed that the most common microorganisms involved in urinary tract infection were: E. coli 33.3\%(n=8) followed by Klebsiella $25 \%(n=6)$,Proteus $16.7 \%(n=4)$, Staphylococcus aureus $12.5 \%(n=3)$, Citrobacter, Acenetobacter and mixed growth were found in $4.2 \%(n=1)$ each. It was found that Amikacin (81\%), Ofloxacin (80\%), Cefixime (90\%) Meropenem (79.2\%), Nitrofurantoin $(72.2 \%)$ ,Piperacillin + Tazobactum (95.2\%) were very much effective against most of the culture isolates .Whereas Staphylococcus aureus was found to be susceptible to Amoxyclav (100\%), Meropenem (66.7\%) and Linezolid (66.7\%). Minor isolates were also found to be susceptible to most of the antibiotics.

\section{Declarations}

\section{ACKNOWLEDGEMENTS}

\section{Not any.}

\section{DECLARATIONS}

\section{Funding: Not any.}

Conflict of interest: Not any.

Ethical approval: Taken from instituitional ethical committee,Bankura Sammilani Medical College,Bankura.

\section{References}

1. Bagga A. Management of steroid sensitive nephritic syndrome: Revised guidelines. Indian Pediatr. 2008;45:203-14.

2. Koskimies O, Vilska J, Rapola J, Hallman N. Long-term outcome of primary nephrotic syndrome. Arch Dis Child 1982;57:544-548.

3. Arneil GC. The nephrotic syndrome. PediatrClin North Am 1971;18:547-59.

4. FeehallyJ, Kendell NP, Swift PGF, Walls J. High incidence of minimal change nephrotic syndrome in Asians. Arch Dis Child 1985; 60: 1018-1020.

5. Sharples PM, Poulton J, white RHR. Steroid responsive nephrotic syndrome is more common in Asian. Arch Dis Child 1985; 60: 1014-17.

6. Mclntosh N, Helms P, Smyth R. Forfar\&Arneil's Test Book of Paediatrics. 6th edition. Edinburgh: ChurchilLinvingstone 2003: 633-636.

7. Neuhaus TJ, Fay J, Dillon MJ. Alternative treatment to corticosteroids in steroid sensitive idiopathic nephrotic syndrome. Arch Dis Child 1994; 71: 522-526.

8. Nash MA, Edelmann CM, Bernstuin J, Barnet HL. Pediatric kidney disease. 2nd edition. Boston/Taronata/London: Little, Brown and company 1978: 1247-1280.

9. Eduardo HG. Effect of lipoid nephrosis cytokine on glomerular sulfated compounds and albuminuria. PediatrNephrol 1995;9:587-93. 
10. Soeiro EMS, Koch VH, Fujimura MD, Okay Y. Influence of nephrotic state on the infectious profile in childhood idiopathic nephrotic syndrome. Rev. HospClinFac Med. 2004;59(5):273-8.

11. Gulati S, kher V , Arora A, Gupta S, Kale S. Urinary tract infection in nephrotic syndrome. Pediatr Infect Dis J. 1996;15:237-240.

12. Wolfish, $P$ Melaine, $P$ Philipps, E Rassies. Role of respiratory viruses in exacerbations of primary nephrotic syndrome. The J of Pediatr. 1986;108: 378-382.

13. Alwadhi RK, Mathew JL, Rath B. Clinical profile of children with nephrotic syndrome not on glucocorticoid therapy but presenting with infection. J Paediatr Child Health. 2004;40:28-32.

14. George $\mathrm{H}$ and McCracken JR. Diagnosis and management of acute urinary tract infection in infants and children. The Pediatr Infect Dis J. 1987;6:107-112.

15. Gulati S, Gupta A, KherV, Sharma RK. Steroid response pattern in Indian children with nephrotic syndrome. ActaPaediatr. 1995;83:530-533.

16. Uwaezuoke SN. Steroid sensitive nephrotic syndrome in children: triggers of relapse and evolving hypotheses on pathogenesis. Italian J Pedia. 2015;41(19):2-6.

17. Gulati S, Arora P, Sharma RK, Kher V , Gupta A, Rai PK. Spectrum of Infections in Indian Children with Nephrotic Syndrome. PediatrNephrol. 1995;9:431-434.

18. Barua T, Sultana R, Babul FK, Iqbal S, Sharma JD et. al.Urinary Tract Infection in Nephrotic Syndrome: A Hospital Based Cross-Sectional Study. ChattagramMaa-O-Shishu Hospital Medical College .Journal $2016 ; 15(2): 41-44$.

19. LC Kundu1, AK Saha2, MK Hassan3, A Kundu4.Urinary Tract Infection in Nephrotic Syndrome - A study of 62 cases at Faridpur Medical College Hospital.Faridpur Med. Coll. J. 2018;13(1):35-39

20. Senguttuvan P, Ravanan K, Prabhu N, Tamilarasi V. Infections encountered in childhood nephrotics in a pediatric renal unit. Indian J Nephrol 2004 Oct; 14: 85-8.

21. Kumar RR1, Ahmer R2. Hidden Urinary Tract Infection in Children with NephrotiSyndrome.www.jmscr.igmpublication.org Index Copernicus Value: 83.27 (p) 2455-0450.

22. Basu B, Baur D, Datta S, Bose M, Saha A (2015) Bacteriological Profile and Sensitivity to Antibiotics of Common Isolates Responsible for Urinary Tract Infection in Nephrotic Children. Int J Nephrol Kidney Failure 1(4): http://dx.doi.org/10.16966/23805498.116

\section{Tables}

Table 1: :Distribution of participants by age group and gender $(n=82)$ 


\begin{tabular}{|l|l|l|l|l|}
\hline Gender & \multicolumn{2}{|l|}{ Age group } & \multirow{2}{*}{ P value } \\
\cline { 2 - 4 } & 2-7(years) & $7-12$ (years) & Total & \\
& No. (\%) & No. (\%) & No. (\%) & \\
\hline Male & 38 & 11 & $49(59.8)$ & \multirow{2}{*}{0.94} \\
\hline Female & 25 & 8 & $33(40.2)$ & \\
\hline Total & $63(76.8)$ & $19(23.2)$ & $82(100)$ & \\
\hline
\end{tabular}

Table 2: Showing urine culture sensitivity pattern

\begin{tabular}{|c|c|c|c|c|c|c|c|c|}
\hline Organism & E. coli & Klebsiella & Proteus & Staph & Citrobacter & Acenetobacter & Mixed & Total \\
\hline Antibiotic & & & & & & & & \\
\hline Ceftriaxone & $3 / 8(37.5 \%)$ & $3 / 6(50 \%)$ & $2 / 4(50 \%)$ & - & $1 / 1(100 \%)$ & - & $1 / 1(100 \%)$ & $10 / 20(50 \%)$ \\
\hline Amikacin & $7 / 8(87.5 \%)$ & $5 / 6(83.3 \%)$ & $2 / 4(50 \%)$ & - & $1 / 1(100 \%)$ & $1 / 1(100 \%)$ & $1 / 1(100 \%)$ & $17 / 21(81 \%)$ \\
\hline Amoxyclav & - & - & - & $3 / 3(100 \%)$ & - & - & - & $\begin{array}{l}3 / 3 \\
(100 \%)\end{array}$ \\
\hline Ofloxacin & $6 / 8(75 \%)$ & $5 / 6(83.3 \%)$ & $3 / 4(75 \%)$ & - & $1 / 1(100 \%)$ & - & $1 / 1(100 \%)$ & $16 / 20(80 \%)$ \\
\hline Cefixime & $\begin{array}{l}7 / 8(87.5 \\
\%)\end{array}$ & $6 / 6(100 \%)$ & $3 / 4(75 \%)$ & - & $1 / 1(100 \%)$ & - & $1 / 1(100 \%)$ & $18 / 20(90 \%)$ \\
\hline Meropenem & $7 / 8(87.5 \%)$ & $4 / 6(66.7 \%)$ & $3 / 4(75 \%)$ & $2 / 3(66.7 \%)$ & $1 / 1(100 \%)$ & $1 / 1(100 \%)$ & $1 / 1(100 \%)$ & $19 / 24(79.2 \%)$ \\
\hline Nitrofurantoin & $8 / 8(100 \%)$ & $3 / 6(50 \%)$ & $2 / 4(50 \%)$ & - & - & - & - & $13 / 18(72.2 \%)$ \\
\hline Linezolid & - & - & - & $2 / 3(66.7 \%)$ & - & - & - & $2 / 3(66.7 \%)$ \\
\hline Pip +taz & $7 / 8(87.5 \%)$ & $6 / 6(100 \%)$ & $4 / 4(100 \%)$ & - & $1 / 1(100 \%)$ & $1 / 1(100 \%)$ & $1 / 1(100 \%)$ & $20 / 21(95.2 \%)$ \\
\hline
\end{tabular}

Table 3:Showing baseline parameters among two groups. 


\begin{tabular}{|l|l|l|l|}
\hline BASELINE PARAMETERS & NEPHROTIC SYNDROME WITH UTI (GROUP A) & $\begin{array}{l}\text { NEPHROTIC SYNDROME WITHOUT UTI } \\
\text { (GROUP B) }\end{array}$ & P value \\
\hline Hb Mean \pm SD & $10.23 \pm 0.75$ & $10.43 \pm 0.75$ & 0.28 \\
\hline E.S.R (Mean \pm SD) & $44.80 \pm 10.15$ & $40.33 \pm 10.45$ & 0.08 \\
\hline TLC (Mean \pm SD) & $11538.33 \pm 1282.19$ & $11074.83 \pm 1575.59$ & 0.11 \\
\hline Protein Mean \pm SD & $4.26 \pm 0.27$ & $4.24 \pm 0.29$ & 0.87 \\
\hline Albumin Mean \pm SD & $2.36 \pm 0.16$ & $2.41 \pm .20$ & 0.30 \\
\hline Cholesterol Mean \pm SD & $422.13 \pm 34.65$ & $307.43 \pm 26.13$ & 0.0001 \\
\hline Urea Mean \pm SD & $17.13 \pm 2.25$ & & $16.75 \pm 2.30$ \\
\hline
\end{tabular}

TABLE 4:SHOWING COMPARISON OF SERUM ALBUMIN AND CHOLESTEROL VALUES BETWEEN TWO GROUPS AMONG DIFFERENT STUDIES

\begin{tabular}{|c|c|c|c|c|c|c|c|c|c|c|c|c|c|}
\hline \multicolumn{14}{|l|}{ STUDY } \\
\hline \multirow{2}{*}{\multicolumn{2}{|c|}{ parameter }} & \multicolumn{2}{|c|}{ Present study } & \multicolumn{2}{|c|}{ Barua et al $^{18}$} & \multicolumn{2}{|c|}{$\begin{array}{l}\text { Kundu et } \\
\mathrm{al}^{19}\end{array}$} & \multicolumn{2}{|c|}{$\begin{array}{l}\text { Senguttuvan et } \\
\mathrm{al}^{20}\end{array}$} & \multicolumn{2}{|c|}{$\begin{array}{l}\text { Kumar et } \\
\mathrm{al}^{21}\end{array}$} & \multicolumn{2}{|c|}{ Basu et $\mathrm{al}^{22}$} \\
\hline & & mean & $\pm s d$ & mean & $\pm s d$ & mean & $\pm s d$ & mean & $\pm s d$ & mean & $\pm s d$ & mean & $\pm \mathrm{sd}$ \\
\hline \multirow[t]{2}{*}{$\operatorname{serum}$ albumin $(\mathrm{gm} / \mathrm{dl})$} & $\mathrm{A}$ & 2.36 & 0.16 & 2.14 & 0.58 & 2.17 & 0.61 & 1.97 & 1.2 & 2.1 & 0.57 & 2.02 & 0.35 \\
\hline & $\mathrm{B}$ & 2.41 & 0.20 & 2.02 & 0.45 & 2.03 & 0.47 & 1.8 & 1.3 & 3.2 & 0.47 & 2.12 & 0.48 \\
\hline \multirow{2}{*}{$\begin{array}{l}\text { serum } \\
\text { cholesterol }(\mathrm{mg} / \mathrm{dl})\end{array}$} & A & 422.13 & 34.65 & 418.94 & 102.28 & 457 & 175 & 381.2 & 135 & 415 & 101 & 369.2 & 81.2 \\
\hline & $\mathrm{B}$ & 307.43 & 26.13 & 352.03 & 24.05 & 370 & 145 & 403.5 & 126 & 350 & 23 & 348.6 & 68.4 \\
\hline
\end{tabular}

\section{Figures}




\section{Distribution of study population according to UTI status}

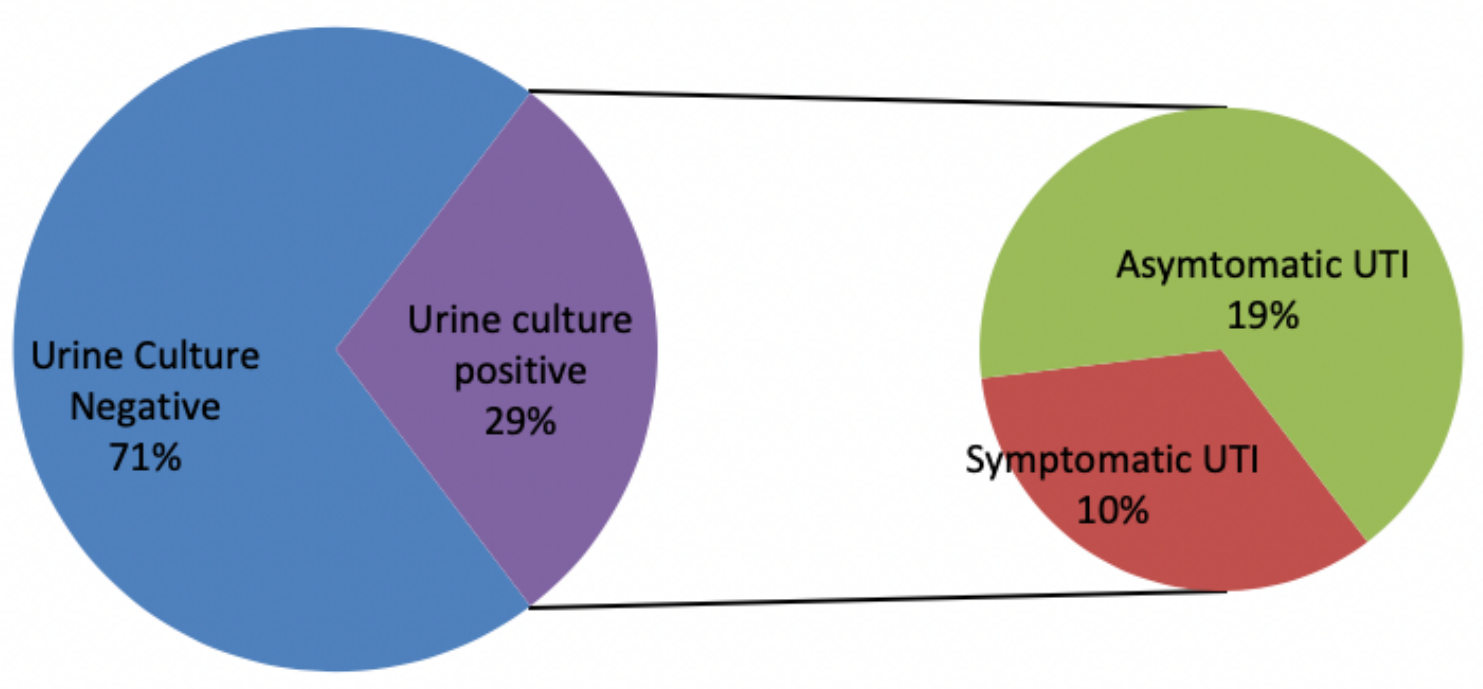

Figure 1

Showing distribution of participants by their UTI status $(n=82)$ and distribution of participants with UTI by symptoms $(n=24)$ 


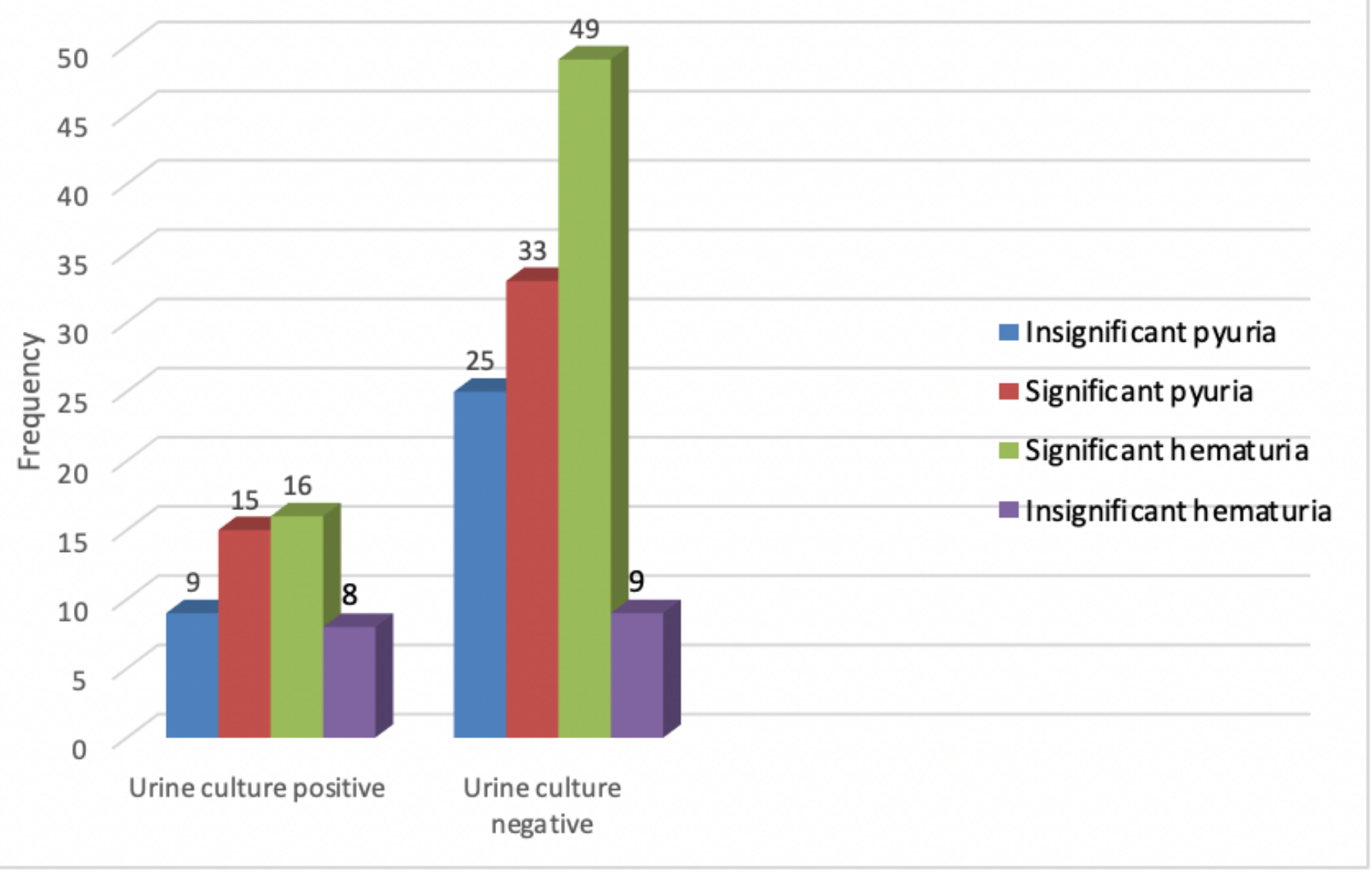

Figure 2

Shows distribution of study population according to hematuria and pyuria 


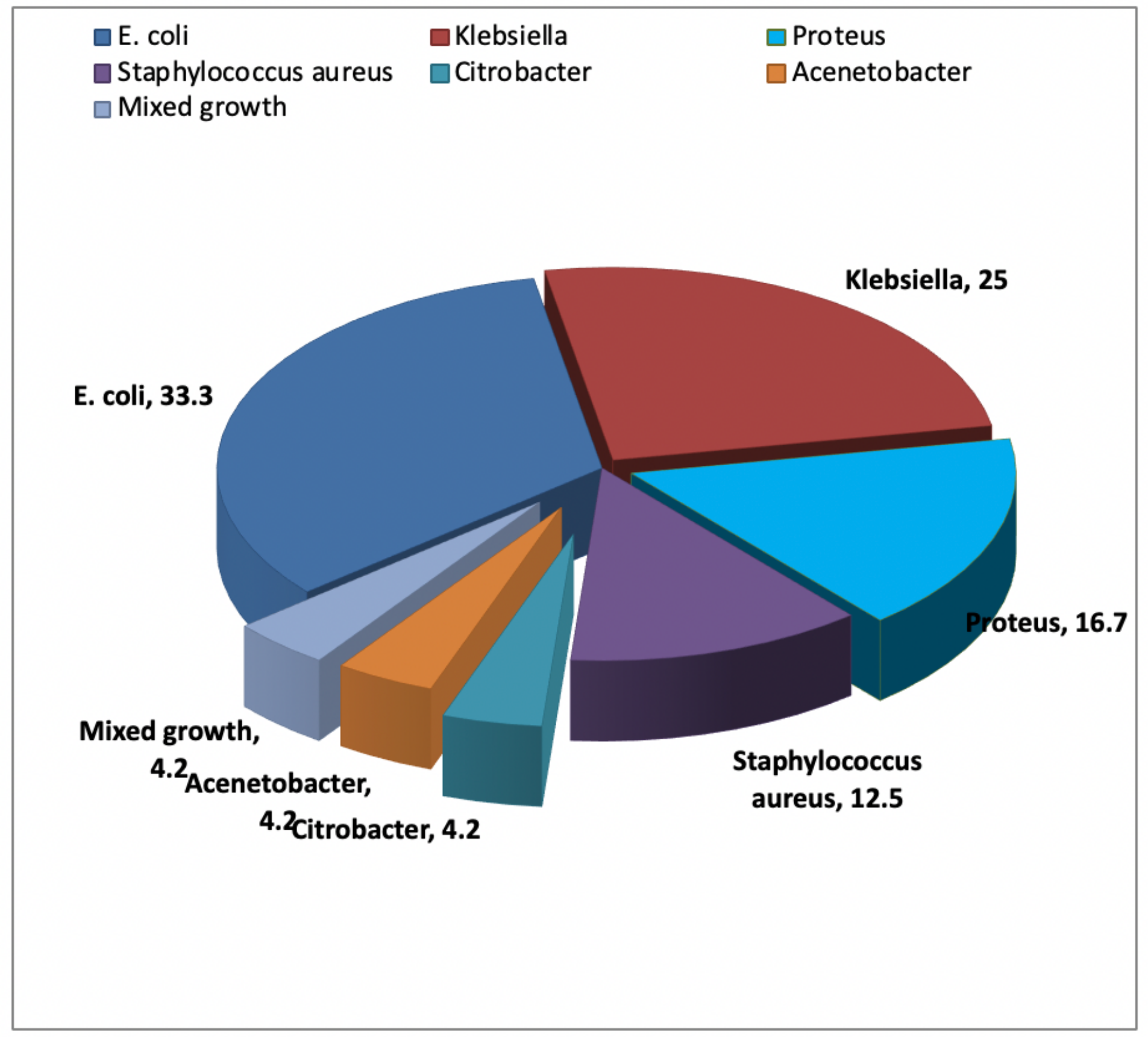

Figure 3

Pie diagram showing causative agents of UTI isolated in the present study $(n=24)$ 